\title{
Optimised accelerated solvent extraction of hexahydro-1,3,5-trinitro- 1,3,5 triazine (RDX) from polymer bonded explosives
}

Tracey J. Temple*a, Catherine Goodwin ${ }^{a}$, Melissa K. Ladyman ${ }^{a}$, Nathalie Mai ${ }^{\text {a }}$, Frederic Coulon ${ }^{\mathrm{b}}$

a Cranfield University, Centre for Defence Chemistry, Defence Academy of the United Kingdom, Shrivenham SN6 7LA, UK

${ }^{\mathrm{b}}$ Cranfield University, School of Water, Energy and Environment, Cranfield MK43 0AL, UK

\begin{abstract}
An Accelerated Solvent Extraction (ASE) method was developed and optimised to extract hexahydro-1,3,5-trinitro-1,3,5-triazine (RDX) from a polyurethane matrix. The ASE method development was benchmarked against Soxhlet extraction with a view to improving extraction efficiency in terms of time and solvent volume. Key parameters for the ASE method development involved selecting the most appropriate solvent, optimising static time, ensuring a safe oven temperature for explosives, determination of a sufficient number of rinse cycles and effective sample preparation. To achieve optimal extraction, cutting the PBX samples to maximise solvent exposure was essential. The use of acetone with a static time of 10 minutes at $100^{\circ} \mathrm{C}$ with three rinse cycles allowed to achieve $97 \% \pm 10 \%$ extraction of RDX from PBX in 40 minutes using $72 \mathrm{~mL}$ solvent. Extraction time was reduced from 48 hours and solvent use by half compared to the standard Soxhlet extraction. To validate the developed ASE method, two other PBX samples containing different quantities of explosive were also fully extracted using the same parameters. Overall, ASE efficiency was comparable to Soxhlet, which places the ASE as a good alternative and shows potential for implementation as a standard method for other polymer based explosives.
\end{abstract}

Keywords: RDX, ASE method, pressurised solvent extraction, Soxhlet extraction, PBX

\section{Introduction}

Robust and reproducible extraction methods to determine the presence and residual concentration of Polymer Bonded Explosives (PBX) are important to inform risk decision making and land management at impacted sites. ${ }^{1}$ PBXs typically consist of a nitramine high explosive combined with a polymer. The most commonly used nitramine explosives include 1,3,5-trinitroperhydro-1,3,5-triazine (RDX) and octahydro-1,3,5,7-tetranitro-1,3,5,7tetrazocine (HMX). ${ }^{2}$ Currently, Soxhlet extraction is a commonly used method to extract nitramines from PBX, however this can take up to 48 hours and use over $150 \mathrm{~mL}$ of solvent per 1 g extraction. ${ }^{3,4}$

Accelerated Solvent Extraction (ASE) has been successfully used to extract chemical components of polymers and was initially developed to replace extraction methods such as Soxhlet, bath sonication and shaking. ${ }^{5,6}$ ASE uses solvent at up to $200^{\circ} \mathrm{C}$ and 1500 psi pressure 
in a closed system to increase extraction efficiency, while minimising preparation time and solvent volume. ${ }^{6}$ Under these conditions the solvent may reach temperatures above its boiling point, which makes it less viscous and increases the solvent's capacity to dissolve the analyte. In addition, the increased pressure forces solvent into the pores of the sample material, making the analyte more readily available for extraction. ${ }^{7,8}$

The use of ASE to extract chemical components of polymers has not been widely reported in the literature, but the extraction of monomers and oligomers and low concentration chemical additives from polymers has been successful. ${ }^{9-11}$ Additives pose a particularly challenging analytical problem, as they are present at very low concentrations, often less than $1 \%$ of the mass of the polymer. ASE has been shown to successfully extract very low concentrations ( 0.02 to $0.1 \%)$ of additives with a relative standard deviation of $20 \%$, which is acceptable for such low concentrations. ${ }^{12}$

To extract a chemical from a polymer it must diffuse from the polymer to the surface followed by transfer through the static solvent layer into the bulk solvent. The rate of mass transfer from the polymer core to the bulk solvent is dependent on the structure and properties of the polymer and solutes, the extraction temperature and the type of solvent ${ }^{10}$. Selecting an appropriate solvent is essential for ASE of polymers as it must be able to dissolve the chemical of interest, while leaving the polymer intact at high temperatures. ${ }^{9,13}$ It has been shown that the most effective way of increasing extraction efficiency is to increase temperature. If it is not possible to increase temperature, mass transfer must be increased by other means such as reducing the size of polymer particles by grinding to reduce the distance from the core of the polymer to the surface. ${ }^{10}$ Achieving high temperatures and grinding the sample present a challenge when extracting high explosive due to safety concerns as the temperature should be kept well below the explosive auto-ignition temperature, and samples should not be ground. ${ }^{14}$

To date, there have been no studies regarding the extraction of explosives from solid explosive matrices using ASE, such as PBX. ASE of explosive residues (RDX and HMX) from soil samples has been developed and successfully used to completely extract RDX and 2,4,6-trinitrotoluene (TNT) and associated degradation products from contaminated soils ${ }^{15,16}$. This method has also been used to extract RDX from animal liver tissue to assess toxicity, demonstrating the flexibility of ASE. ${ }^{17}$ Another study comparing four different extraction methods (ASE, Soxhlet, Microwave Assisted extraction and supercritical fluid extraction) for HMX, RDX and TNT from soil showed that ASE was the most efficient with $90 \%$ recovery. For all tested explosives, ASE extraction efficiency was comparable or better than Soxhlet extraction and was reproducible with a maximum of $10 \%$ standard deviation. ${ }^{18}$

The aim of the paper was to develop and optimise a robust analytical method for the extraction of RDX from PBX. The optimised ASE method was successfully validated using two additional PBX compositions to demonstrate its broader applicability. 


\section{Materials and methods}

\subsection{PBX composition}

PBX samples were obtained from an industrial supplier as $100 \mathrm{~g}$ slabs $(10 \times 5 \times 2 \mathrm{~cm})$ as described in Table 1. The PBX samples contain small amounts other additives for stability and performance, although this research focussed specifically on the extraction of the energetic component.

Table 1: Composition of the PBX samples based on Safety Data Sheets including only the relevant percentages of the explosive extracted. ${ }^{19-21}$

\begin{tabular}{|c|l|c|c|c|c|c|c|}
\hline $\begin{array}{c}\text { PBX } \\
\text { Sample }\end{array}$ & Explosive & $\begin{array}{c}\text { Explosive } \\
(\%)\end{array}$ & $\begin{array}{c}\text { Polymer } \\
(\%)\end{array}$ & $\begin{array}{c}\text { Aluminium } \\
(\%)\end{array}$ & $\begin{array}{c}\text { Auto- } \\
\text { ignition } \\
\text { temperature } \\
\left({ }^{\circ} \mathrm{C}\right)\end{array}$ & $\begin{array}{c}\text { Density } \\
\left(\mathrm{g} \mathrm{cm}^{-3}\right)\end{array}$ & $\begin{array}{c}\text { Sensitiveness to } \\
\text { Friction (N) } \\
(\text { BAM Friction) }\end{array}$ \\
\hline A & RDX & 64 & 9 & $20 \%$ & 206 & 1.65 & $>360$ \\
\hline B & HMX & 87 & 6 & - & 230 & 1.65 & $>353$ \\
\hline \multirow{2}{*}{$\mathrm{C}$} & RDX & 20 & \multirow{2}{*}{6} & $25 \%$ & 209 & 1.79 & 151 \\
\cline { 2 - 7 } & $\begin{array}{l}\text { Ammonium } \\
\text { Perchlorate }\end{array}$ & 43 & 6 & & & \\
\hline
\end{tabular}

\subsection{Optimisation of Accelerated Solvent Extraction Method for PBXA}

A slab of PBX-A was scored using a ceramic knife and cut into $1 \mathrm{~g}$ cubes $\left(1 \mathrm{~cm}^{3}\right)$. To decrease the volume and depth of solvent penetration required the $1 \mathrm{~g}$ samples were cut into smaller cuboids of similar volume (approximately $0.5,0.125,0.065$ and $0.008 \mathrm{~cm}^{3}$, respectively). Samples of PBX-A were placed into stainless steel solvent extraction cells $(33 \mathrm{~mL})$ filled with Ottawa sand, or inside a cellulose thimble with and without sand to reduce solvent volume. Cells were placed in the ASE, and an initial 14 minute method was programmed according to the Application Note for extraction of traditionally used explosives, such as TNT from soil..$^{22}$ Briefly, using the standard mode with a system pressure of $1500 \mathrm{psi}$, oven temperature $100{ }^{\circ} \mathrm{C}$, oven heating time 5 minutes, static time set at 5 minutes, the rinse volume was $60 \%$ of the cell volume and a rinse cycle with a $200 \mathrm{~s}$ purge (Table 2 ). These conditions were used as the baseline for further optimisation.

The PBX-A extraction method was systematically optimised by changing one perimeter at a time e.g. solvent, static time, rinse cycles, sample volume and cell preparation, as summarised in Table 2. The oven temperature, pressure, flush volume and oven heating time were not optimised. 
Table 2: Summary of the initial method and the conditions optimised during method development.

\begin{tabular}{|c|c|c|}
\hline Parameter & $\begin{array}{l}\text { Application Notes } \\
\text { method }\end{array}$ & $\begin{array}{c}\text { Conditions tested for optimisation } \\
\text { in this study }\end{array}$ \\
\hline Cell size $(\mathrm{mL})$ & 33 & Unchanged \\
\hline Initial volume (mL) & 38 & Unchanged \\
\hline Pressure (psi) & 1500 & Unchanged \\
\hline Oven temperature $\left({ }^{\circ} \mathrm{C}\right)$ & 100 & Unchanged \\
\hline Oven heating time (min) & 5 & Unchanged \\
\hline Solvents & $\begin{array}{l}\text { Acetone or } \\
\text { methanol }\end{array}$ & Acetonitrile or acetone or methanol \\
\hline Static time (min) & 5 & $5 ; 10 ; 20 ; 30$ \\
\hline No. of rinse cycles & 1 & 3 \\
\hline Rinse volume $(\% ; \mathrm{mL})$ & $60 ; 24$ & Unchanged \\
\hline Purge time (s) & 200 & Unchanged \\
\hline $\begin{array}{l}\text { PBXA sample volume } \\
\left(\mathrm{cm}^{3)}\right.\end{array}$ & 1 & $1.0,0.5,0.13,0.07$ and 0.008 \\
\hline ASE cell preparation & Ottawa sand & $\begin{array}{l}\text { Ottawa sand/ thimble and sand/ } \\
\text { thimble only }\end{array}$ \\
\hline
\end{tabular}

Extracts (approximately $60 \mathrm{~mL}$ ) were diluted by 100 using the extraction solvent, filtered $(0.2$ $\mu \mathrm{m}$ syringe filter) and analysed by HPLC immediately.

\subsection{Accelerated Solvent Extraction of PBXB and PBXC}

PBX-B (1 g) and PBX-C $(1 \mathrm{~g})$ were scored and cut into cuboids $\left(0.008 \mathrm{~cm}^{3}\right)$ using a ceramic knife on filter paper. The PBX-B and PBX-C pieces were then transferred to a thimble, which was placed in a stainless steel extraction cell $(33 \mathrm{~mL})$. The cells were loaded into the ASE and the PBX were extracted with acetone at $100{ }^{\circ} \mathrm{C}, 1500$ psi for 3 ten minute rinse cycles with a 5 minute oven heating time, 200 second purge time and a rinse volume of $60 \%$. Extractions were completed in triplicate.

A sub-sample of the resulting extracts were diluted accordingly, filtered and analysed by HPLC.

\subsection{Soxhlet Extraction}

PBX-A ( $1 \mathrm{~g})$ was cut into $2 \mathrm{~mm}^{3}$ pieces and placed in a glass thimble in a Soxhlet extractor. ${ }^{3}$ The RDX was extracted from PBX-A with acetone $(150 \mathrm{~mL})$ at $70^{\circ} \mathrm{C}$ for 48 hours. The resulting RDX extract was made up to $200 \mathrm{~mL}$, diluted accordingly and analysed by HPLC.

\subsection{Calibration solution preparation}

The 50 ppm stock solutions of RDX and HMX respectively were prepared by dissolving accurately weighed standards in acetonitrile. Calibration standards, made daily by subsequent dilutions of the stock solution in acetonitrile, ranged from a concentration of 5 to $50 \mathrm{ppm}$. 


\subsection{Instrumental Analysis}

HPLC analyses were performed on a Waters Alliance 2695 separation module coupled to a Waters 996 photodiode array detector (PDA). Chromatographic separations were carried out isocratically with a NovaPak C8 $(3.9 \mathrm{~mm} \times 150 \mathrm{~mm}, 4 \mu \mathrm{m})$ column from Waters maintained at $35{ }^{\circ} \mathrm{C}$. The mobile phase consisted of $50 \% \mathrm{ACN}$ and $50 \% \mathrm{H}_{2} \mathrm{O}$ with $0.1 \%$ formic acid with a flow-rate of $1.5 \mathrm{~mL}$ min-1 and the injection volume was $10 \mu \mathrm{l}$. RDX peak was identified by comparing its retention time and absorption spectrum in the samples with those of the standard solution. RDX was monitored at $235 \mathrm{~nm}$.

The HPLC method was validated by assessing: (i) Specificity (analysis of solution of PBX); (ii) Linearity (measure of the correlation coefficient for each standard from the linear regression analysis in the concentration range of 0.05 to50 $\mu \mathrm{l} / \mathrm{ml}$ ); (iii) Limit of Detection (LOD), Limit of Quality (LOQ) (measure of the residual standard deviation of the responses and slopes of the regression equation of the calibration curve (root mean square error approach)) and (iv) Precision (measure of the relative standard deviation of ten injections of each compounds at two concentrations). The results of the method validation are displayed in Table 3.

Table 3: Summary of method validation results.

\begin{tabular}{|r|l|}
\hline Test & Results \\
\hline Precision (\%)@25 $@ 1 / \mathrm{ml}$ & 0.10 \\
\hline$@ 2 \mu 1 / \mathrm{ml}$ & 0.38 \\
\hline Linearity $\left(\mathrm{r}^{2}\right)$ & 1.00 \\
\hline LoD $(\mu \mathrm{l} / \mathrm{ml})$ & 0.033 \\
\hline LoQ $(\mu \mathrm{l} / \mathrm{ml})$ & 0.099 \\
\hline
\end{tabular}

\section{Results and Discussion}

\subsection{ASE method development and optimisation}

The ASE method was based on a Dionex Application Note designed to extract traditional explosives from soil, using methanol or acetone (Table 1). ${ }^{22}$ However, polymers are more difficult to extract as the matrix must first swell to allow the solvent access to the RDX. Therefore, test solvents were chosen based on their use in the application note (i.e. methanol and acetone) and their ability to dissolve RDX and to swell the polymer. RDX is most soluble in acetone and acetonitrile especially at elevated temperatures. ${ }^{23}$ In addition, acetone promotes swelling of the polymer. ${ }^{24}$ Methanol was also tested as it was used in the Application Note. RDX solubility in the chosen solvents is summarised in Table 3. PBXA samples were extracted with the three solvents for five minutes (static time) at an oven temperature of $100{ }^{\circ} \mathrm{C}$, and 1500 psi. 
The percentage recovery of RDX from $1 \mathrm{~g}$ of PBX-A was low for all tested solvents. Acetone was the most efficient with a recovery of $11 \%$. Of the three solvents RDX is the most soluble in acetone and it is the preferred extraction solvent for Soxhlet, ${ }^{3,4}$ which is often a good indication of solvents that may be successful for ASE. ${ }^{25}$ Recovery of RDX using acetonitrile was $6 \%$. Methanol was the least efficient achieving only $2 \%$ recovery of RDX, probably due to a combination of poor RDX solubility and limited swelling effect (Table 4). Therefore, acetone was selected as the preferable solvent for the extraction of RDX from PBXA and was used in all following extractions.

Table 4: RDX solubility in acetonitrile, acetone and methanol ${ }^{23}$ and the percentage recovery of RDX from PBX when varying solvent.

\begin{tabular}{|l|c|c|c|c|}
\hline Solvent & $\begin{array}{c}\text { RDX Solubility } \\
\text { at } \mathbf{2 0}{ }^{\circ} \mathbf{C}\end{array}$ & $\begin{array}{c}\text { RDX Solubility } \\
\text { at higher } \\
\text { temperature }\end{array}$ & $\begin{array}{c}\text { Solvent Boiling } \\
\text { Point }\left({ }^{\circ} \mathbf{C}\right)\end{array}$ & $\begin{array}{l}\text { Percentage } \\
\text { Recovery }\end{array}$ \\
\hline Acetonitrile & 5.5 & $14\left(60^{\circ} \mathrm{C}\right)$ & 81.6 & $6 \%$ \\
\hline Methanol & 0.24 & $1.27\left(64.5^{\circ} \mathrm{C}\right)$ & 64.7 & $2 \%$ \\
\hline Acetone & 8.2 & $17\left(60^{\circ} \mathrm{C}\right)$ & 56.3 & $11 \%$ \\
\hline
\end{tabular}

Following solvent selection, the recommended next step in the optimisation process is to vary oven temperature. ${ }^{26}$ However, ASE has not previously been used to extract explosive formulations and the high temperatures may increase the likelihood of thermal decomposition 15. Therefore, the temperature was held constant at $100^{\circ} \mathrm{C}$ to ensure that it remained below the auto-ignition temperature of $\operatorname{RDX}\left(197{ }^{\circ} \mathrm{C}\right)$ and PBXA $\left(206^{\circ} \mathrm{C}\right) \cdot{ }^{27,28}$ Unable to alter the temperature, the next stage was to optimise the static time. Increasing the static time exposes the sample to solvent for longer, allowing more time for the polymer to swell and the RDX to dissolve. The static time was increased progressively from five to thirty minutes. When the static time was increased from five to ten minutes RDX recovery improved from $11 \%$ to $32 \%$. Increasing the static time from ten minutes to thirty minutes had no further effect on extraction efficiency of RDX, as it is likely that the system had reached equilibrium between extracted $\mathrm{RDX}$ in the solvent and RDX remaining in the polymer (Figure 1). Therefore, the optimal static time used in all following experiments was ten minutes. 


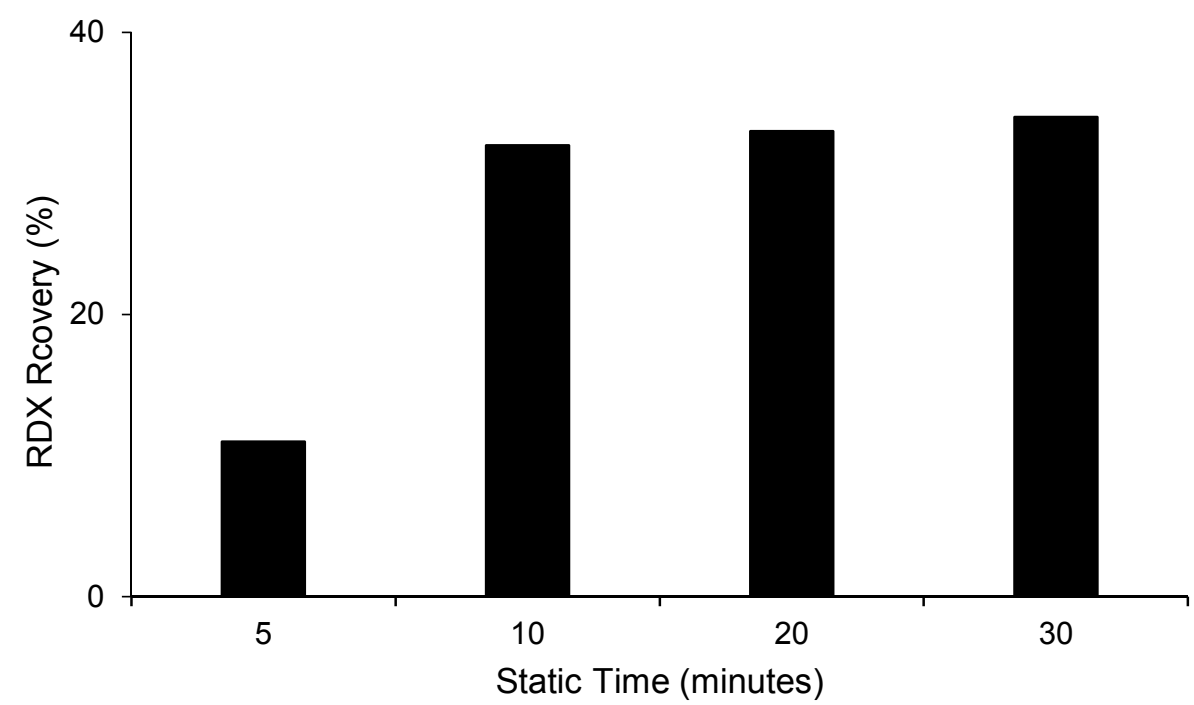

Figure 1: Percentage recovery of RDX from PBXA when varying static time from five to thirty minutes.

In order to shift the equilibrium, the ASE method was further optimised to include rinse cycles during the extraction. This allows fresh solvent to be added, which helps to maintain a favourable extraction equilibrium and encourage further dissolution of the sample. ${ }^{26} \mathrm{Up}$ to this point, each extraction only had the one rinse cycle as per the Application Note method, (Table 1) which meant that at the end of the ten minute static time the sample was rinsed with $60 \%$ of the cell's volume of solvent e.g. $20 \mathrm{~mL}$ rinse for a $33 \mathrm{~mL}$ cell. The ASE enables the user to choose the number of rinse cycles for each extraction, which splits the volume of rinse solvent between the number of cycles. The PBXA extraction was split into three ten minute rinse cycles, distributing an equal proportion of the solvent between each rinse cycle, which increased the percentage of RDX recovered by $16 \%$ to a total of $48 \%$ (Figure 2).

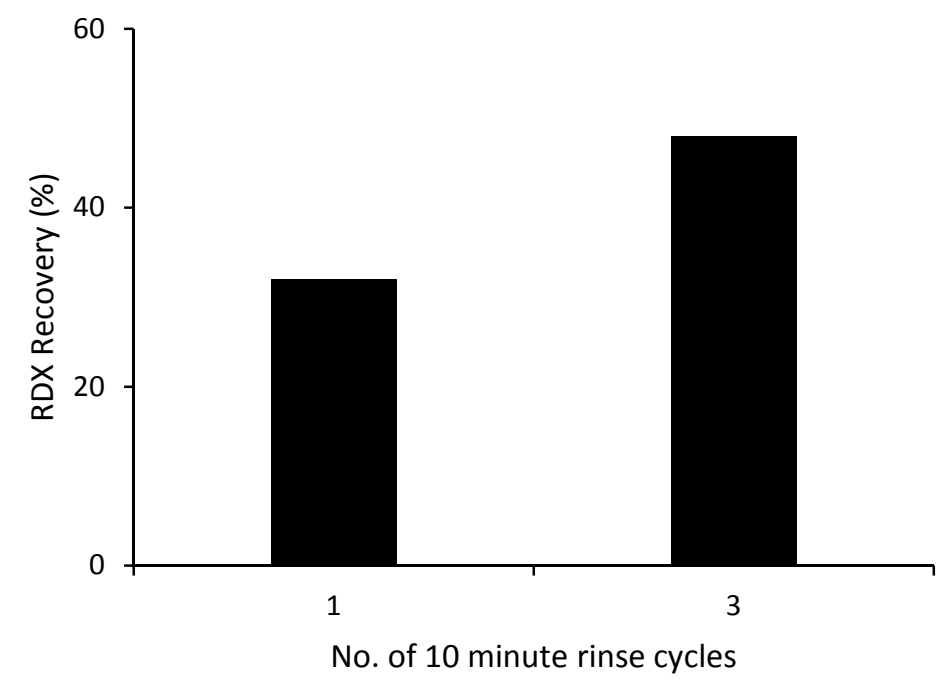

Figure 2: Percentage recovery of RDX from PBXA when rinse cycles were added to the extraction.

It was clear that exposing the sample to fresh solvent increased extraction efficiency, although not achieving $100 \%$ suggesting that the solvent cannot ingress further into the polymer. 
However, due to the explosive nature of the sample cutting the sample further to increase surface area was avoided at this time. Therefore, the volume of solvent introduced to the cell was increased by reducing the amount of Ottawa sand in the cell surrounding the sample by half. The PBXA sample was placed in a porous cellulose thimble, which leaves more space in the cell for solvent. The thimble was used with and without sand to achieve optimum solvent efficiency.

As expected, increasing the volume of solvent in the cell by removing the sand improved the extraction efficiency to $58 \%$. Placing the sample in a thimble with sand resulted in a similar percentage recovery to the samples placed in a cell with sand only (48\% and $50 \%)$ (Figure 3 ).

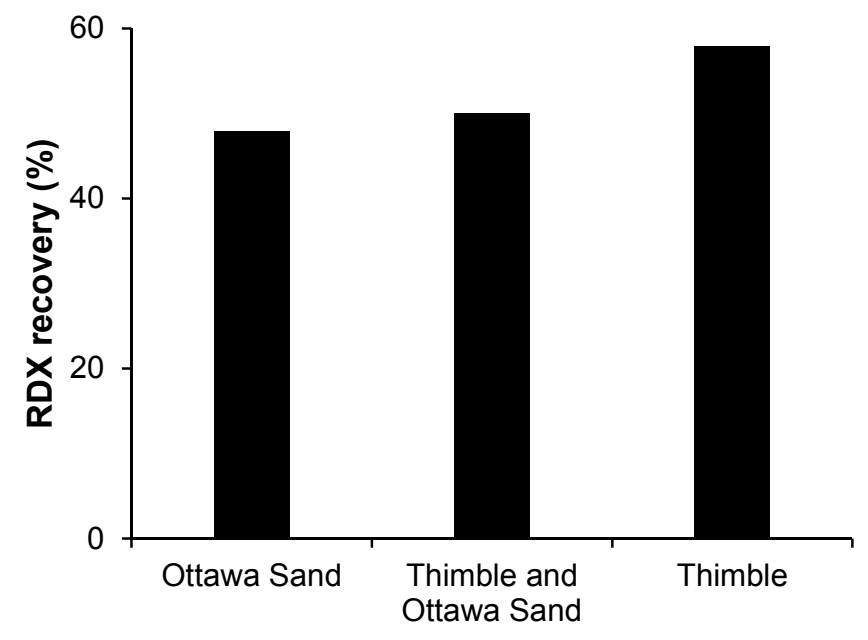

Cell Fill

Figure 3: Effect of increasing the volume of solvent in the cell by removing Ottawa sand.

The improvement in the extraction efficiency by removing Ottawa sand was minimal, and may be overcome by further optimisation to minimise solvent use. However, it may be necessary to compromise the volume of solvent for safety when extracting explosive formulations as the coarse sand may pose a friction hazard for some formulations. For all further extractions samples were placed in a cellulose thimble.

Having followed the recommended ASE method development for optimisation and improved extraction to $58 \%$ by optimising method parameters, the final step was to optimise the sample preparation. It is usually recommended grind samples to increase surface area and availability of the material to be extracted, however this would not be suitable for explosive formulations. Therefore, the PBXA sample was cut into smaller uniform pieces to determine the optimal volume. The smallest size was limited by practicality, cutting the pieces smaller than $0.008 \mathrm{~cm}^{3}$ was difficult, and resulted in RDX particles escaping the matrix. The cut PBXA was transferred to a cellulose thimble.

Increasing the surface area resulted in a significant increase in extraction efficiency. The smallest pieces $\left(0.008 \mathrm{~cm}^{3}\right)$ resulted in complete extraction achieving $100 \%$ recovery of RDX. To confirm that $100 \%$ recovery was achieved, the extraction was repeated twice. Repeating the extraction enabled $100 \%$ recovery of RDX from the slightly larger $0.07 \mathrm{~cm}^{3}$ pieces as well 
(Figure 4). Overall, increasing the surface area achieved the greatest percentage improvement in extraction efficiency although this was the least preferred optimisation route due to the necessity of cutting the explosive.

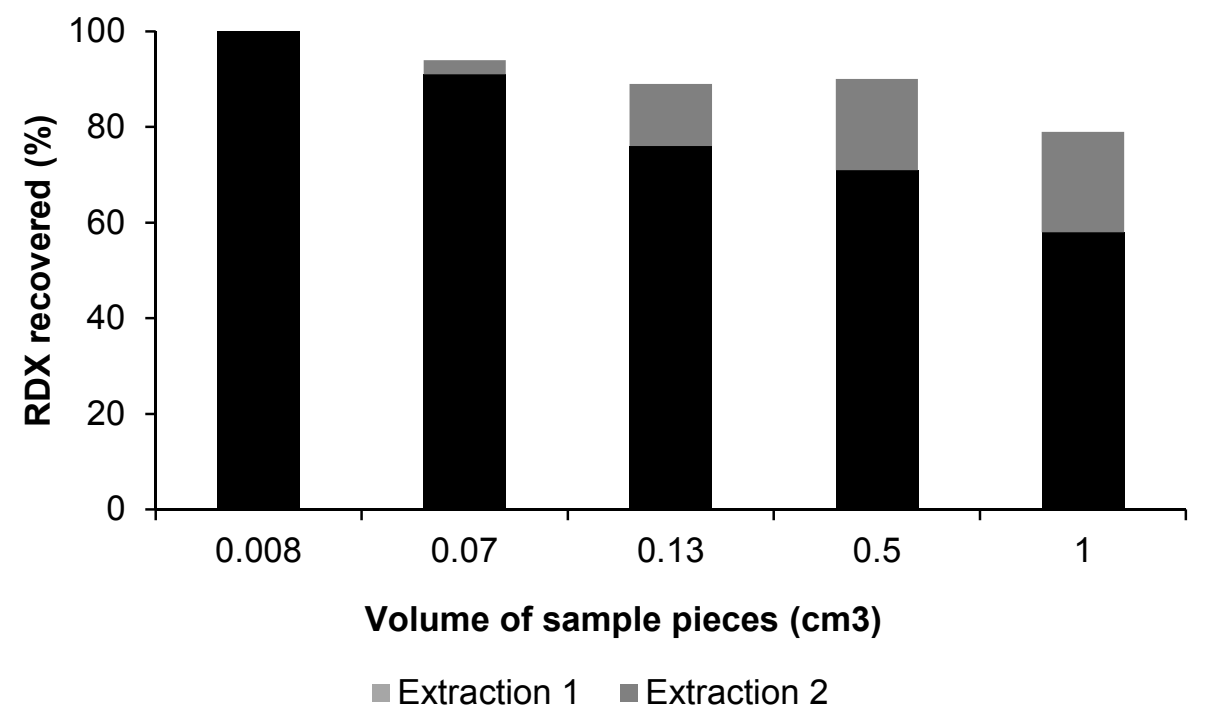

Figure 4: Percentage of RDX recovered from 1.0, 0.5, 0.13, 0.07 and $0.008 \mathrm{~cm}^{3}$ pieces of PBX A.

Once the conditions to achieve 100\% extraction has been determined, the optimised method was repeated on 6 samples of PBXA to determine reproducibility. The extraction efficiency averaged $97 \%$ with a standard deviation of $13 \%$, which is similar to the standard deviation of other ASE methods found in the literature. ${ }^{15,17}$ Whilst this is often acceptable in the literature for other methods, it should be possible to improve the precision by continued optimisation. For example, RDX mass may have been lost during cutting of PBXA although care was taken to ensure all material was account for. As a control measure, at least three replicates of each sample should be extracted to overcome any reproducibility issues.

The optimised ASE method for the extraction of explosive from PBX used acetone, a ten minute static time, with three rinse cycles, using $60 \%$ rinse volume at $100^{\circ} \mathrm{C}$ and 1500 psi with a 200 second purge summarised in Table 5. This method achieved 100\% extraction of RDX from PBX in forty minutes, and used approximately $60 \mathrm{~mL}$ acetone.

Table 5: Summary of the optimisation for the extraction of RDX from PBXA

\begin{tabular}{|c|l|c|c|}
\hline Step & Optimised parameter & Optimised condition & Percentage Recovery \\
\hline 1 & Solvent & Acetone & $11 \%$ \\
\hline 2 & Static time & 10 minutes & $32 \%$ \\
\hline 3 & Rinse cycles & 3 & $48 \%$ \\
\hline 4 & Cell preparation & Thimble only & $58 \%$ \\
\hline 5 & Sample size & $0.008 \mathrm{~cm}^{3}$ & $100 \%$ \\
\hline
\end{tabular}




\subsection{Soxhlet extraction of RDX from PBX}

To ensure the novel ASE extraction method was comparable to current best practice, PBX-A was extracted by Soxhlet, which is an established method in the literature. ${ }^{3,4}$ The PBX-A sample was acquired from an industrial source, and the accompanying data sheet stated that it contained $64 \%$ RDX. Sub-samples for extraction were cut from the slab and were assumed to contain $0.64 \mathrm{~g}$ of RDX per $1 \mathrm{~g}$ of PBX-A. The calculated mass of RDX extracted was based on the actual mass of the cut sample. The Soxhlet extraction of PBXA took forty eight hours and $150 \mathrm{~mL}$ of acetone, and achieved an average of $90 \% \pm 0.5 \%$ recovery of the RDX (2 replicates). The two methods are compared in Table 6. During the extraction RDX precipitated around the edge of the round bottomed flask as solvent evaporated, which created an explosive hazard and therefore required close monitoring.

Table 6: Comparison of optimised ASE method and Soxhlet

\begin{tabular}{|l|c|c|}
\hline Parameter/Method & ASE & Soxhlet \\
\hline Solvent (volume) & Acetone $(60 \mathrm{~mL})$ & Acetone $(150 \mathrm{~mL})$ \\
\hline Time & 40 minutes & 48 hours \\
\hline Temperature & $100^{\circ} \mathrm{C}$ & $78^{\circ} \mathrm{C}$ \\
\hline Solvent exposure & 3 rinse cycles & continuous \\
\hline Efficiency & $97 \% \pm \%$ & $90 \% \pm 0.5 \%$ \\
\hline
\end{tabular}

The ASE method was more efficient, achieving an average of $97 \%$ RDX extraction compared to $90 \%$ using Soxhlet. Even though the improvement in extraction efficiency appears small, the reduction in time was significant with the ASE only taking forty minutes in total, compared to forty-eight hours for Soxhlet. Also, the ASE used only $60 \mathrm{~mL}$ of solvent, compared to at least $150 \mathrm{~mL}$ Soxhlet.

The ASE also provides broader benefits, in addition to resource efficiency. For example, the ASE is a closed system where solvent is automatically dispensed to the sample, whereas Soxhlet is more manual and requires frequent solvent refill. This causes a potential explosive hazard when solvent evaporates causing solid explosive to precipitate in the round-bottomed flask adjacent to the heating mantle. Overall, the ASE significantly reduces extraction time as it can automatically run up to twenty-four samples. It also requires less intensive monitoring compared to Soxhlet, which enables faster sample throughput.

\subsection{Validation of optimised method}

The optimised method was applied to two additional PBXs to determine the applicability of the method. PBXB contained 87\% HMX; PBXC contained 20\% RDX, 43\% ammonium perchlorate, and $25 \%$ aluminium. The method enabled the successful extraction of HMX from $\mathrm{PBXB}$, with an average of $99 \%$ recovered in a single extraction (Figure 5).

Recovery of RDX from PBXC was not as efficient with an average of $92 \%$ recovered after two extractions, however the consistency of PBXC made it difficult to cut and the pieces used were slightly larger than the optimal $0.08 \mathrm{~cm}^{3}$ possibly contributing to the slightly lower recovery 
(Figure 5). In addition, PBXC is denser than the other two PBX's which may make it more difficult for solvent to ingress into the polymer to aid explosive extraction.

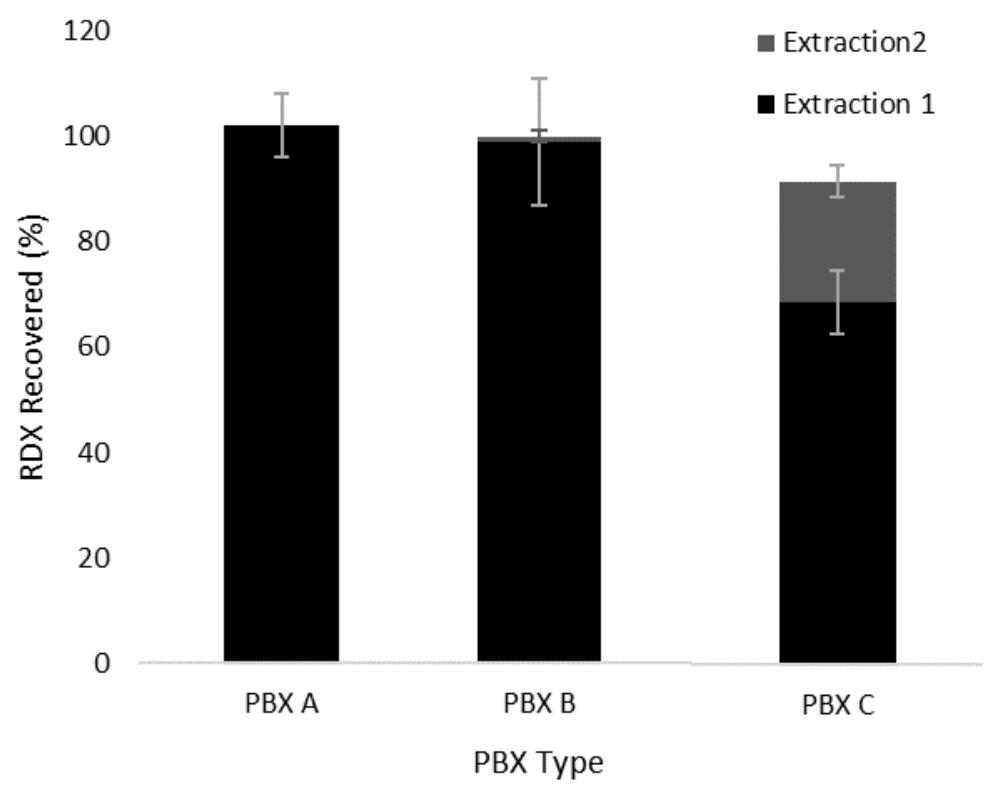

Figure 5: Comparison between extraction efficiency of the optimised method for three different PBX (3 replicates).

\section{Conclusion}

The first reproducible method for the complete extraction of RDX/HMX from PBX using ASE was successfully optimised and validated. The method development aimed to follow the recommended optimisation procedures, however the extraction of explosives was more complex due to additional safety concerns e.g. auto-ignition and friction hazard. It was considered unsafe to optimise the temperature beyond $100^{\circ} \mathrm{C}$, and placing the samples in a cellulose thimble reduced friction hazard whilst maintaining extraction efficiency. It was not considered ideal to cut the PBX smaller than necessary for the extraction therefore this optimisation step was consciously left as the last option. However, it was necessary to carefully cut the PBX to achieve full extraction. The optimised extraction method for the extraction of RDX/HMX from PBX using ASE was $100{ }^{\circ} \mathrm{C}, 1500$ psi, with a 10 minute static cycle, three rinse cycles in acetone and a 200 second purge achieving an average of $97 \%$ extraction. The samples were prepared by cutting to increase surface area, and placing in cellulose thimbles. The total extraction time was 40 minutes, and used $60 \mathrm{~mL}$ solvent, which is a significant reduction when compared to Soxhlet extraction, which takes 48 hours and over $150 \mathrm{~mL}$ solvent. It may be possible to reduce the extraction time further by reducing the static time between each rinse cycle. The success of this method for three different PBX suggest that it would be applicable to other polymer based explosives. In addition, further work should include extraction of all components of the PBX, and it may be possible to develop a method with consecutive extractions to separate the different components.

\section{Acknowledgements}


The authors would like to thank RWM Italia for provision of the materials, and James Padfield for advice and guidance. We would also like to thank Cranfield University, Centre for Defence Chemistry for support.

\section{References}

(1) Giergielewicz-Mozajska, H.; Dabrowski, L.; Namiesnik, J. Critical Reviews in Analytical Chemistry 2017, 31 (3), 149-165.

(2) Akhavan, J. The Chemistry of Explosives; The Royal Society of Chemistry: Cambridge, 2011.

(3) Kumar, M.; Ladyman, M. K.; Mai, N.; Temple, T.; Coulon, F. Chemosphere 2017, 169, 604-608.

(4) DuBois, F. W.; Baytos, J. F. Weathering of explosives for twenty years; New Mexico, 1991.

(5) Fisher, J. A.; Scarlett, M. J.; Stott, A. D. Environmental Science \& Technology 1997, 31 (4), 1120-1127.

(6) Richter, B. E.; Jones, B. a; Ezzell, J. L.; Porter, N. L.; Corporation, D.; Way, T.; Box, P. O. Analytical Chemistry 1996, 68 (6), 1033-1039.

(7) Vandenburg, H. J.; Clifford, A. A.; Bartle, K. D.; Zhu, S. A.; Carroll, J.; Newton, I. D.; Garden, L. M. Analytical Chemistry 1997, 70, 1943-1948.

(8) Richter, B. E.; Jones, B. A.; Ezzell, J. L.; Porter, N. L.; Avdalovic, N.; Pohl, C. Analytical Chemistry 1996, 68, 1033-1039.

(9) Vandenburg, H. J.; Clifford, A. A.; Bartle, K. D.; Carlson, R. E.; Carroll, J.; Newton, I. D. The Analyst 1999, 124 (11), 1707-1710.

(10) Lou, X.; Janssen, H.-G. J.; Cramers, C. A. Analytical Chemistry 1997, 69, 1598-1603.

(11) Möller, J.; Strömberg, E.; Karlsson, S. European Polymer Journal 2008, 44 (6), 15831593.

(12) Zhang, Y.; Du, Z.; Li, A.; Tu, A.; Yu, W.; Zou, J. Analytical Methods 2013, 5 (19), 5112.

(13) Primbs, T.; Genualdi, S.; Massey Simonich, S. Environmental Toxicology and Chemistry 2008, 27 (6), 1267-1272.

(14) Walsh, M. E.; Ramsey, C. A.; Jenkins, T. F. Chemosphere 2002, 49 (10), 1267-1273.

(15) Campbell, S.; Ogoshi, R.; Uehara, G.; Li, Q. X. Journal of Chromatographic Science 2003, 41 (6), 284-288.

(16) Onuska, F. I.; El-Shaarawi, A. H.; Terry, K.; Vieira, E. M. Journal of Microcolumn Separations 2001, 13 (2), 54-61.

(17) Pan, X.; Zhang, B.; Cobb, G. P. Talanta 2005, 67 (4), 816-823. 
(18) Ungrádová, I.; Šimek, Z.; Vávrová, M.; Stoupalová, M.; Mravcová, L. International Journal of Environmental Analytical Chemistry 2013, 93 (9), 984-998.

(19) RWM Italia. Safety data sheet PBXN-109; Ghedi, Italy, 2010; Vol. 2006.

(20) Explosive Hazard Data Sheet Polymer Bonded Secondary Explosive PBX111; Ghedi, Italy, 2005.

(21) RWM Italia. Explosive Hazard Data Sheet Polymer Bonded Secondary Explosive PBX110; Ghedi, Italy, 2005.

(22) Dionex. Application Note 328: Extraction of Explosives from soils by Accelerated Solvent Extraction (ASE); Sunnyvale, CA, 2011.

(23) Sitzmann, M. P. AD-773 078: Solubilities of high explosives: Removal of high explosive fillers from munitions by chemical disslolution; Silver Spring, Maryland, 1973.

(24) Jinlong, L.; Junming, Y.; Yucun, L.; Tao, C.; Liang, Z.; Environment, S. of C. E. and; China, N. U. of. China Adhesives 2015, No. 10, 12-15+22.

(25) Lou, X.; Janssen, H.-G.; Cramers, C. A. Analytical Chemistry 1997, 69, 1598-1603.

(26) Thermo Sceintific. Dionex ASE 350 Accelerated Solvent Extractor Operator's Manual; United States, 2011.

(27) Harris, J. Thermochimica Acta 1976, 14 (1-2), 183-199.

(28) Safety data sheet PBXN-109; Ghedi, Italy, 2010; Vol. 2006. 